\title{
Approaches to training in companies
}

\author{
Patrizia Magnoler ${ }^{a}$, Mariachiara Pacquola ${ }^{b}$ \\ ${ }^{a}$ Università di Macerata, Italy, patrizia.magnoler@unimc.it,0000-0003-0653-5084 \\ ${ }^{b}$ Università di Macerata, Italy, cpacquola@hotmail.com,0000-0003-0653-5084
}

\begin{abstract}
The need to address generational change and the challenges of a global market in terms of maintaining productivity require small and medium enterprises, mainly of an artisanal nature, to rethink training. The challenges mainly concern production capacity, which is increasingly problematic given that demand does not allow for long-term schedules and enhancement of human resources. There are many tensions and just as many needs for improvement, and training is therefore the space in which to collect and rework in order to restore a new perspective of sustainable and quality change.

This study presents a process of collaboration between universities and businesses, in which the former provide the framework for the activation of mechanisms that make use of work analysis, while the latter provide the appropriate support (time and opportunities for discussion) to allow for a review of the proposed training model and trainer functions in a dynamic and complex production environment.
\end{abstract}

Keywords: small-medium enterprises, vocational didactics, work analysis, skills development

\section{Introduction}

Changes in production modes in Italian small and medium enterprises (SMEs), operating within the global luxury market that values and seeks out a combination of "beauty" and "tradition and historicity in manual creation", show a tendency towards production of the highest-quality goods, with almost spasmodic attention to detail. This seems to be the precondition for covering - in international trade - a specific space that can secure employment and the development of these companies.

SMEs in the footwear sector fully meet these characteristics and are currently at the heart of the European Agenda ${ }^{1}$ due to the problematic nature of the relationship between supply and demand for services related to the development of the skills needed to cope with the emerging challenges. Research conducted by national and European social and business organisations describes a supply of training that is essentially unstructured (non-formal and non-certified), free-floating (i.e. not tied to a development strategy and not connected to real needs) and episodic (ad hoc). Action in support of services for training and employment in the sector also lack effectiveness due to the use of traditional training methodologies and absence of coordination with other companies and research centres.

SMEs, for their part, still tend to consider training as a sunk cost, rather than a real investment, or even as a double cost. It often happens that training time overlaps with working time, thus creating the need to replace the trainee with another worker of the same level. The difficulty in preparing "effective" training that is able to respond to emerging needs arises from the inability of companies that are still very wedded to the family craft organisational structure to identify real needs as well as from the inadequacy of training models that should equip the workforce with new strategies for addressing changes in production. Note that, among SMEs in the high-quality footwear industry, major changes are taking place: a) the collections to be produced have doubled and this results in a decrease in the time available to analyse new models and convert them into production processes; b) collections include footwear models that, to intercept fashion and consumption, consist of materials and forms that require a substantial review of working practices; c) the scheduling of production is more complex, less and less linear and punctuated by predictable rhythms, characterised by orders for production of limited volume but with major variety in the products themselves.

The company usually responds to new demands and different production processes with the actual resource available: the professional culture for the quality of the product based on experience transmitted from one individual to

${ }^{1}$ Report: "The European footwear industry: structure, social dialogue, the future" promoted by the European Confederation of the footwear industry and Industriall European Trade Union, 2014, Brussels, Belgium. 
another in a standard apprenticeship mode. Accordingly, we must start from rediscovery of tacit or partially expressed knowledge in order to build on in-house expertise. Training must accept this challenge and focus on formalising and capitalising on the existing knowledge of experienced workers to resolve a number of issues that today are of fundamental importance for the very survival of SMEs:

- accelerate the development of basic skills of apprentices/young workers in increasingly short periods to cope with the problem of generational change,

- increase the versatility of workers and the company's ability to address new and atypical work situations;

- use the whole range of formalisation of practical knowledge to train new recruits and give life to smooth forms of knowledge management that can be used to solve emerging problems.

These are the reasons that led the University of Macerata to undertake a joint project in partnership with the Footwear Polytechnic and in particular with the Corrado Maretto company ${ }^{2}$, an SME operating in the Brenta Footwear District, to test the dissemination and application of knowledge gained in the field of Francophone research (Olry \& Parage, 2008, Samurçay \& Pastré, 1998, Olry \& Vidal-Gomel, 2011) and national research (Magnoler, Pacquola \& Tescaro, 2014), inspired by the perspectives of vocational education (Pastré, Mayen \& Vergnaud, 2006) and the clinic of activity (Clot, 2008). These perspectives can be used to enhance existing worker knowledge, to provide techniques for their recognition and conceptualisation as well as to activate individual and collective analysis processes on practices and emerging issues.

\section{Knowledge of practices within the community}

"Industrial craft" production involves the use of advanced technology and employment of workers with major manual experience who can handle complex professional actions with a high level of attention. Apparently, these actions can be identified as routine; in fact, they are "repetition without repetition" as the sequence of operations and movements is continually recalibrated depending on the variables presented by the materials and the forms being worked. The abundant information that the worker assumes very quickly through the body (sight, touch and feel) finds a way to be managed and optimised through shared references in the community that makes up the actual culture of the company in question (the genre). Common action organisers (Bru et al, 2007) can then be found: quality criteria, economy of action, time/activity/quality ratio - these help to maintain a constant level of excellent production.

Any training course that seeks to introduce improvements must take account of the genre expressed through practice and jargon, the set of expressions that the workers use to communicate within the company. This relates to the particular terms or constructs used to describe and give meaning to work situations, to the product manufacturing stages: it is a dense social language about pragmatic concepts (Samurçay and Pastré, 1995) interpreted contextually in the situations and processes that arise most often in the work. These are particularly significant language constructs because they contain a summary of the elements included in instant decisions and in situational assessments, and they are then disambiguated and translated in communicable terms for the benefit of the training of other workers in the industry.

The genre is born of the relationship between prescribed work and actual practice (Leplat, 1997). The prescription (the way that a particular activity must be carried out) is not always available in a structured form within an SME. But even in cases where it is possible to find clarification of the tasks and the criteria for their completion, it can never be considered a representation of the action. It is the actual task, the way in which the community has reinterpreted the prescription, by selecting the possible actions from among those imposed, that gives life to the system of actions (Clot, 2008) and the culture of the trade. The criteria for evaluation are also an inherent part of the culture: "It is through the genre that workers mutually appreciate and judge each other" (Clot, 2008, p. 108). This type of culture also has an anticipation function (Berthoz, 2013; Rivoltella, 2014); it is a memory for evaluation and prediction, which continuously feeds new visions of action in relation to new problems and products. It is the mastery of the genre that allows the individual to mature a style of his/her own, a personal method in which to interpret action, either with the body or with representations of which he/she is mostly conscious. And it is the variability of style that allows for different strategies that, when shared and accepted as effective, feed the culture of the community. Clot summarises (Rabardel, 1995) thus: "It is in the variation of production activity that the activity becomes constructive. This is the source of invariance and not only of its scope" (Clot, 2008, p.23). Style arose from this unconscious dynamism characterised by moments of repetition, discovery of the problem, changes, consolidation or elimination of a mode of action that is no longer considered sufficient in relation to the product, to the style itself.

Genre can also be an obstacle to change and innovation when it becomes an absolute reference and leaves no room for individual freedom for research, or where it provides an "already given and approved" reference, which means that the individual cannot evolve without feeling excluded from the production process.

Training has the fundamental task of understanding what knowledge permeates the genre, of discovering how the style is developed in order to achieve two fundamental objectives. a) To enable each individual to engage in conscious construction of himself/herself as a capable subject (Rabardel, 1995) by putting him/her in a position of in-depth knowledge of the organisation of the action itself, of interdependence between the actions of others and of the knowledge embodied in them. And this is where the epistemisation (Pastré, 2011), of the "shaping" of the knowledge

${ }^{2}$ The Maretto Company is a family-run SME with 130 employees, a contractor and with subcontracts with five French multinational brands of luxury women's shoes. 
embodied in the action takes place. b) To proceed with the restructuring of operational schemes and then the preparation of the schema/situation report (Vergnaud, 1996) that characterises the contextualised competence through job analysis and evaluation of the properties of the artefact (Simondon, 2012). The latter is one of the basic steps that have become the focus of study of Vocational Education (Pastré, Vergnaud \& Mayen, 2006). The action schema is not intended as a limiting or binding structure but as a support for the action that the individual builds from repeated experiences of similar situations. An inherent part of this is a generative potential that "is no doubt measured through the number of obstacles that the person may face" (Beguin and Clot, 2004).

\section{From academic research to in-company training}

To respond to these challenges in the Industrial District of "Riviera del Brenta", we proceeded - from $2008^{3}-$ to carry out different lines of research interventions (Cappelletti, 2012; Dolbec \& Prud'Homme, 2009; David, 2000; Mérini and Ponté, 2008; Tochon and Miron, 2004; Carrier and Fortin, 2003), based on the theoretical and methodological framework of Vocational Education ${ }^{4}$, through a team consisting of experts from business process analysis, pedagogy-teaching-training practitioners and work psychologists.

The results relate to the following:

- the structuring of learning processes in informal and non-formal contexts (Pacquola \& Pacquola, 2014) Materials and procedures were provided based on explicit statements of expert knowledge through their vertical transmission between seniors and juniors, or horizontal transmission between workers with different skills. The objective was the development of the skills required for a specific job or, in more successive workplaces, the same manufacturing process familiar to them all in order to enable the company to address generational change and the need for interchangeability of people within the production process led by the manual conveyor (Magnoler, Pacquola \& Tescaro, 2014);

- the usability of the materials and the repertoire of activities and tasks in a formal context for vocational training. According to standard practice, a teacher in a vocational school at the Footwear Polytechnic is a practitionerexpert who demonstrates the actions to be undertaken by the students/apprentices. Training is delivered to broaden pedagogical and didactic skills, to construct mediation and for the management of communication to improve teaching in the classroom (Pacquola, Magnoler \& Pacquola, 2014);

- $\quad$ capitalising on the tacit knowledge of some trades (fitter, assembler and model maker), which have become the explicit assets of the Industrial Area. The gap in the definition of "prescribed task" has been partially resolved through validation of the repertoires constructed by practical experts from several leading companies in luxury footwear: this process of co-reflection made it possible to change the deductive direction (from prescribed to acted) in a recursive process (from acted to prescribed, to acted in a new situation). The result is not therefore a fixed product produced by an external community, but a dynamic instantiation of existing knowledge and innovative strategies born of practice;

- the definition of a repertoire of training devices designed within a multidisciplinary team, able to enrich each other's proposals and visions considering the knowledge and expertise of the others. The training feasibility study, which was based on the analytical skills of the processes and organisation of the work for identification of the business's critical situations for learning, interacts strongly with psychological attention to subjective knowledge in the work and the construction of teaching resources for the enhancement and full usability of knowledge.

The Taylorist approach to the division of labour in tasks with a high level of specialisation, had led operators to automate action, thus losing the systemic vision and perception of the end result; the outcome of this labour organisation entailed an attitude of lack of responsibility for "what comes before and what comes after" the single task and created a gradual stratification of errors during the production process. Working, in training terms, with operators on their practices contributed to a reduction in these problems by acting on the development of greater consciousness of the action (moving away from automatism to increased perception of the changes effected by the action itself), in verbalising the action (being able to communicate to each other what we have done and why), as well as in mutual interdependence and individual accountability.

The analysis of the training undertaken from 2008 to the current day also leads to a reflection on the role of the trainer. From the initial to the most recent experiences, three different approaches can be traced in addressing the need to achieve different objectives: "learn the job", "epistemise action" and "address the new".

\section{Learn the job}

The initial finding, by a trainer operating within SMEs, is that "only the groups themselves" can implement lasting change in their professional environment (Clot et al., 2000). This means that the trainer has to walk "with" the workers and, to do so, must go outside the classroom, into the workplace and undertake a shift from traditional classroom teaching-learning methodologies by assuming a listening and accompanying approach.

${ }^{3}$ La participation du Politecnico della Calzatura aux projets européens LDV "Au delà de la salle" 2008-2010,"Au delà de l'apprentissage formel" 2010-2012,"Compétences pour l'Europe" 2012-2014.

${ }^{4}$ The methodology was learned from the research intervention group through transfer of concepts, methodologies and best practices in intervention by French projects developed on the Osmose and Forsimpad projects, funded by the European Leonardo da Vinci programme. 
The main knowledge to be acquired relates to "the trade", as understood by the company and its workers. Listening to the head of the company leads to an understanding of the representations of the production process, the causes of problems, of solutions implemented and trajectories deemed sustainable and viable. Listening to workers enables a comparison between the corporate vision and the actual activity and its overlap with the statements of the workers, even if they conflict with one another, the different operating models that regulate action and interaction, the underlying pragmatic concepts, the complexity of the system of cause-and-effect attribution, the repertoires of culturally permitted achievable decisions and actions.

Information, reflections, comments and judgements coming from the commissioning management are aimed at people who "do not take responsibility, cannot act autonomously, do not cooperate with each other, continually request the support of conveyor line managers or send out shoes with defects". The workers, on the other hand, refer to the difficulty of production and enhancement of human resource: "there is no rule, for every shoe there is a different problem, we have no time and everyone has to make do". They particularly mention problems in relation to the following:

- the organisation of work: absence of precise and shared operational guidelines, of a common quality standard for evaluation of the results of each individual operation and the final result of the assembly segment, as well as the lack of specific knowledge among managers on ergonomics of the work positions;

- the work culture: the contrast between the managerial organisation of the work, of an executive nature, focussed on making and not on collaboration and sharing of solutions as well as the need to be able to enjoy training that develops proactivity, taking responsibility and professional autonomy;

- the management and development of human resources and the culture of learning: limited capacity for assessment of the skills of the workers, as well as absence of training programmes other than apprenticeships, which take a long time for the development of the skills and "distracts" the expert from his/her duties, thus creating difficulties in maintaining the pace of the work.

It is necessary to align corporate culture with professional culture through analysis of the work and of individual and collective activities. The trainer who adopts the vocational education methodology "plays" the role of the one who has to learn from the other (Schwartz, 1997, p. 20). The possible lack of technical knowledge of the trade means that he/she is initially in an asymmetrical situation with respect to the employee, which allows him/her to look carefully at the automatic actions and enables detection of the first lines of investigation through dialogue. He/she can therefore progressively enter into a rich and dense collective discourse: enunciations, apparently neutral ways of saying or not saying, which guide the actions of individuals and the community.

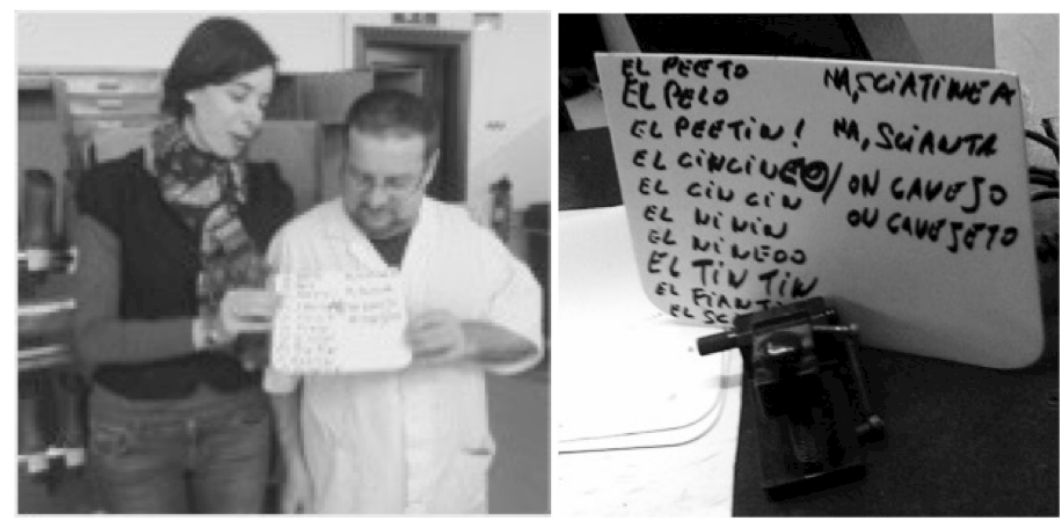

Fig. 1 A worker shows the trainer the indicator reference system, encoded in company jargon, which collectively guides the regulations of the action towards the expected outcomes.

\section{Epistemise action}

During analysis of the work and, later, in the training design, the goal of the trainer is to support the epistemisation of the knowledge of senior workers (Pastré, 2012), by starting his/her discovery of the knowledge, representations and organisers of his/her own actions. The long and difficult path that leads from verbalising the knowledge stored in the sensory perceptions, in mental representations, involves the use of specific methods and techniques for explanation. Two passages of encounter between the individual and his/her own activities, documented in the video, are particularly effective in achieving the objective. In the first phase of analysis, the worker is placed in a situation of self-encounter in the presence of the researcher supporting him/her with questions of specification, to help him/her find negotiated words "to say the action." In the second stage, the cross-referenced self-encounter continues with the trainer, with the experienced worker showing his/her own video to junior workers. This technique facilitates optimum use of the transformative and training potential of the encounter among the different experiences and their tacit knowledge. The trainer accepts and uses the contradictions, obstacles, sociocognitive conflicts, digressions and connections, as these are valuable doors to the discovery of individual action and the relationship with collective knowledge. He/she discovers, 
together with the group, the means of avoiding mistakes, of managing time, of evaluation and regulation of actions in the event of unforeseen but resolvable situations.

The set of simple and crossed-referenced self-encounters brings out the different skills and enhances subsequent performances, the different operating models that underlie performance along with problems related to body posture as well as the fatigue resulting from certain actions that are the cause of the physical and psychological discomfort of the worker.

Sharing this wealth of knowledge is strategic and forward looking, but expensive; it requires valuable time, which the company tends to be unwilling to grant if it does not perceive an immediate advantageous effect in terms of individual and collective performances and competitiveness for the company. For this reason, the development of the relationship between the expected and the actual task of the worker is ensured by the trainer as follows:

- he/she initially processes, conceptualises, formalises and capitalises on the results, using all the scientific and methodological methods and tools offered by Vocational Education (drafting of action plans, of operational models and of classroom situations);

- then he/she designs teaching mediators to make the learning process more effective and efficient using the didacticism of the content, thereby making it easier to understand the concept and notions to be transferred and by adapting the learning content based on an understanding of the ability of the beneficiaries,

- finally, he/she proposes a reification of practical knowledge to the company, so that it can be recognised, validated and shared so that they can recognise the limits of the desired change.

During this phase, there are several important passages for the continuation of the intervention. The new representative form of the knowledge, which is mainly iconic, enables the workers to recognise the meaning of their action and it becomes a valuable shared reference in collective activation of cognitive processes, such as remembering, rethinking and designing action in all its complexity; this allows individual style to be revisited and genre to be shared explicitly. These external representations are operative cognitive tools assisting the activity of the worker by acting as a support and/or guide (Rogalsky \& Samurçay, 1993). They also become teaching mediators to be used as training supports in two different contexts: in the company during the job-classroom alternation and during the training activities in a formal context to improve the effectiveness of the training-work relationship. The school-work alternation is enhanced by a different vision, not only as a succession of theoretical learning and practical application, but as practical learning through analysis of practice with theoretical and technical tools belonging to the disciplines taught.

The documented activities of the individual work role are also an important reference for analysis of the quality of professional actions. Where appropriately reviewed with experts from outside the company, it provides a targeted reformulation of the task, which, first, facilitates the trainer's work and, second, defines the indicators to be monitored during evaluation of the training and of action in context.

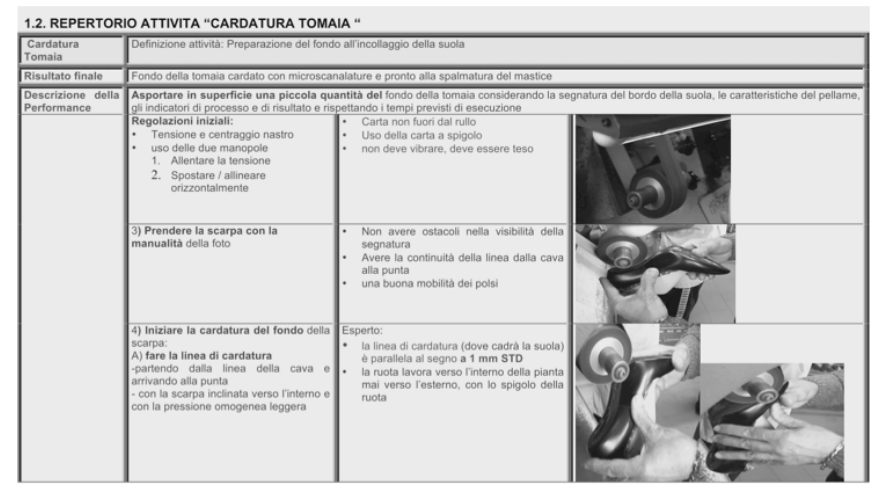

Fig. 2 An example of activity repertoire.

Simultaneously, while the trainer makes it easier to understand the jargon, by clarification of the concepts and criteria for evaluation and validation of the action, his/her language itself becomes more understandable and acceptable to corporate stakeholders because he/she is now referring to something experienced, something lived together. For example, the concepts of situation classes or operating models, which previously would have been completely ignored by the workers as unnecessary and incomprehensible, are now recognised as important elements for promoting the independent appropriation of an effective method of knowledge transfer. 


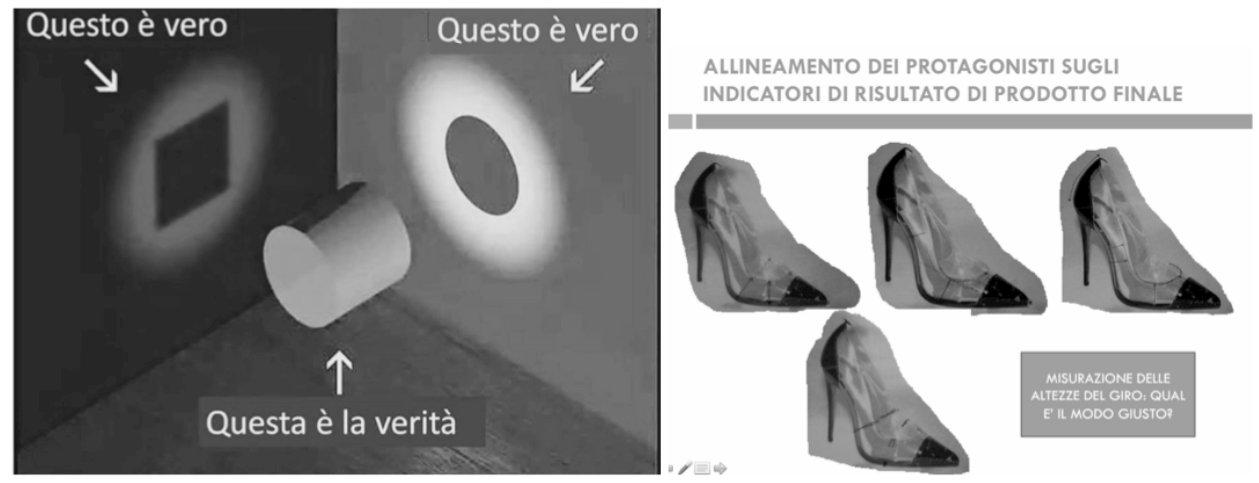

Fig. 3 Examples of detection of practices of different workers in order to achieve a shared model.

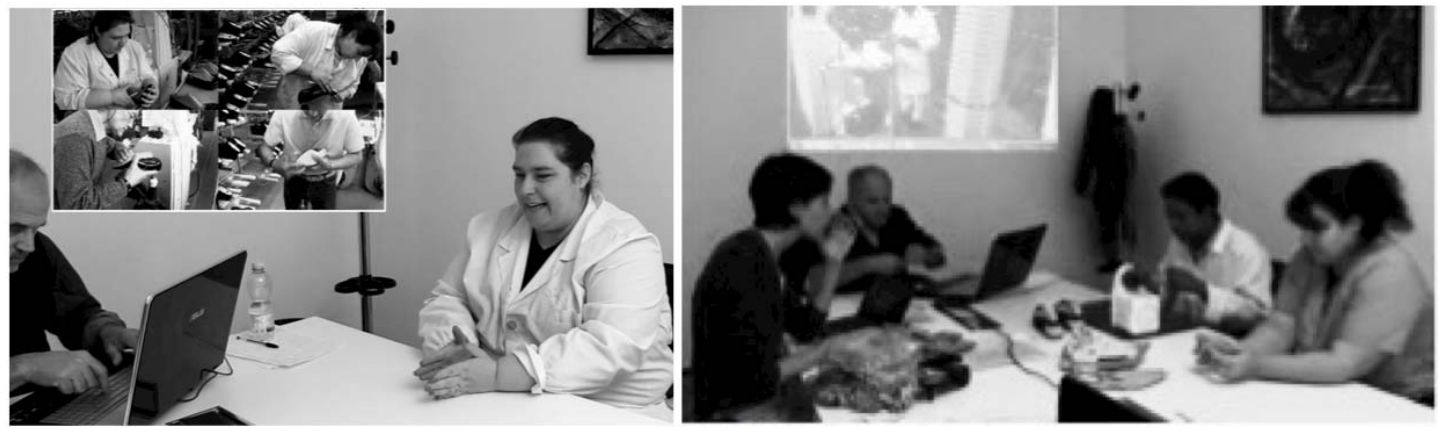

Fig. 4 Work analysis for identification and comparison of work styles.

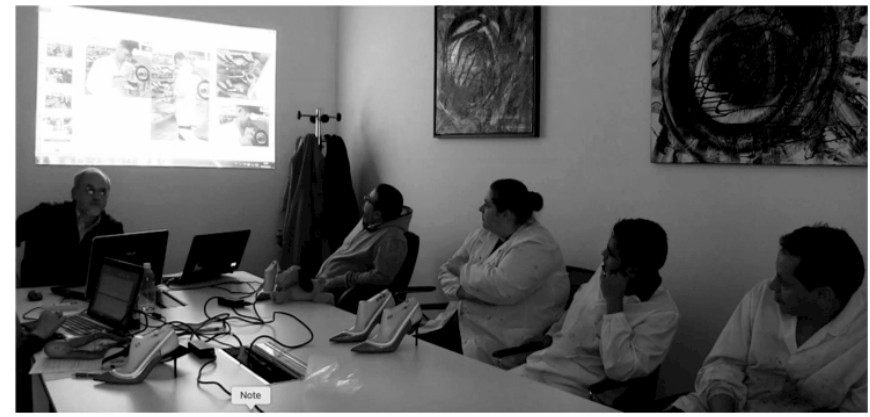

Fig. 5 Analysis of the customer-supplier relationship within the work process with the operators of the "Sole Application" assembly line segment.

But there are also outcomes in this phase. The recursive encounter, extended to different production points along the manual conveyor, brings out the partial and final outcome indicators at the end of each activity. It therefore develops awareness of the responsibility of each operator in the systemic relationship between customer (workplace upstream from him/her) and internal supplier (workplace downstream from him/her). It gradually matures into a common shared standard for action in relation to quality and error correction. From this basis, the following can be derived:

- $\quad$ customisation of the training activity, based on the conceptualisation needs of each worker and of subgroups;
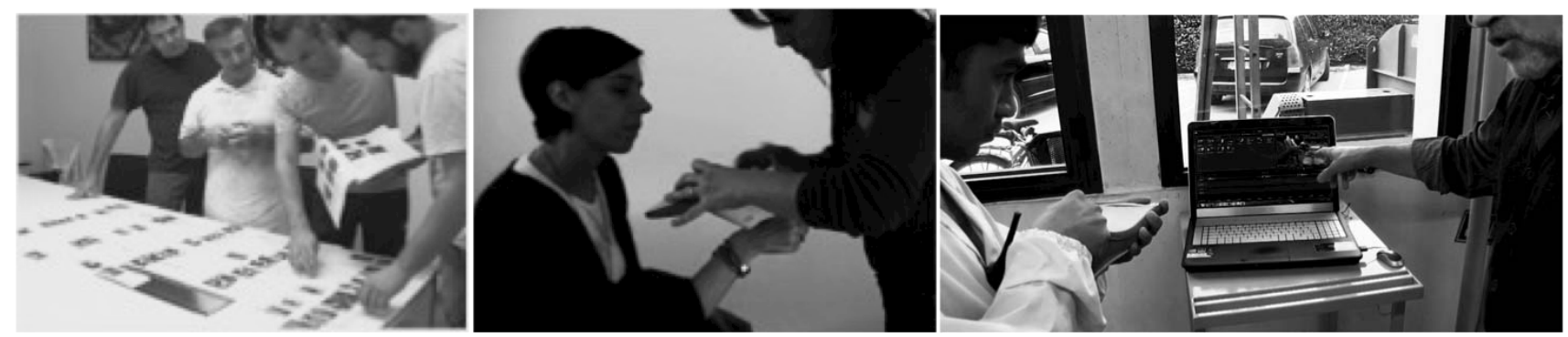

Fig. 6 Training sessions 
- $\quad$ definition of the duration and frequency of training sessions, thus creating modular training through the design of educational capsules capable of generating the expected and crucial changes, by taking account of the needs of the production process;

- $\quad$ preparation of a process of training evaluation of the learning outcomes by practical implementation, which is culturally recognised by the company. The evaluation is carried out through individual and collective reflection based on the video recording of the experiences of the cross-referenced self-encounters. This method leads to a new way of sharing the results of each activity within a complex production process.

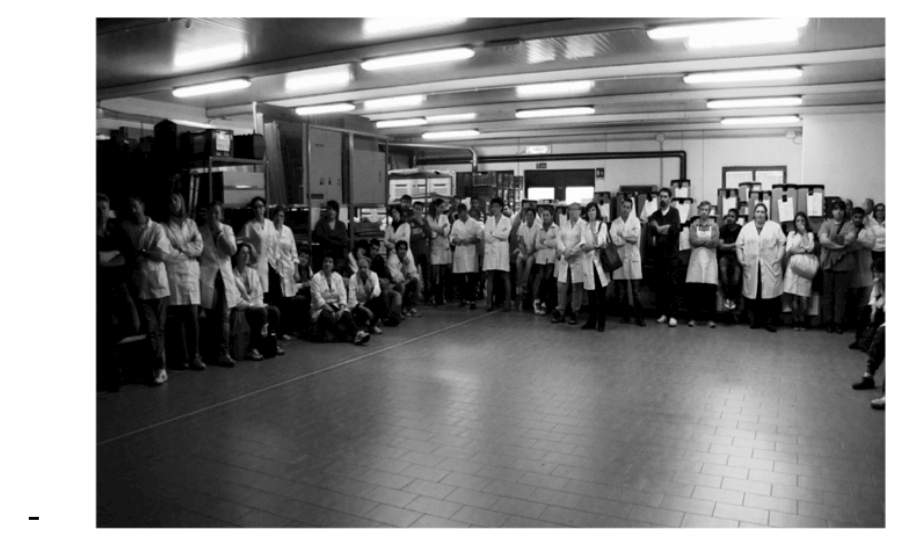

Fig. 7 Involve all company actors to encourage transformation of the genre.

\section{Addressing the new}

The trainer has, up to now, facilitated two fundamental phases: shaping the production process and actual activities interpreted by workers; and constructing devices for didactic transposition of the knowledge used in formal and informal learning situations in the workplace. At the start, however, the problem relating to change in the characteristics and forms of footwear to meet market needs was highlighted.

The production of shoes with materials other than leather (fabrics, various polyurethanes) and with challenging shapes (heel-form ratio) involves the need to address new problems in real time. Hence, training for skills development in a relationship between senior and junior, or between those with the same level of expertise, to improve the level of quality of the action, is not the only winning strategy. The trainer's role must be rethought, but currently, there are only a few examples of situations that allow a glimpse of the direction of change. Some cases addressed in the company in 2015 led to the identification of new options for training work that also encourages reflections on approaches, on spaces for action to be managed in the interplay between work and places for reflection on action. Note particularly the reference to types of complex situations that present independent variables, such as the model and material for production of the shoe, and dependent variables, namely the existing action schemas that no longer manage to support production quality. The training challenge is to know how to act, in real time, at the level of detection of practical knowledge, as well as for the construction of the procedures for action to provide clarity on operational diversity, which needs to be compared with the obtained and the desired results. What the trainer observes is no longer just the operating mode of the individual for the single activity, but the various interpretations of the subjects who engage in changing their own actions based on existing knowledge. The process made visible is the transformation of the schema/situation relationship and it is on this learning potential, connected to the unknown task, that training attention is focussed. The trainer monitors the stages of exploration as an observer and deduces reifications based on attempts made by workers to rework them by formalising them over a brief timescale. The training provides support for post-action reasoning to allow the rapid redesign of action considering an examination based on data and identified variables.

Fig. 8 provides an example of the final production by the trainer after observation: he/she goes over the actions again and restores them to enable reflection that might be called second level. It is no longer only the reconstruction of the sequence of the individual actions, but a graphic transposition of processes and related problems to be proposed to the operators for simultaneous comparison. The objective is to provide an overview of the various possible methods for decision-making, which takes account of the many variables and outcomes of different ways of interpreting the task. 


\section{Approaches to training in companies \\ Magnoler, Pacquola}

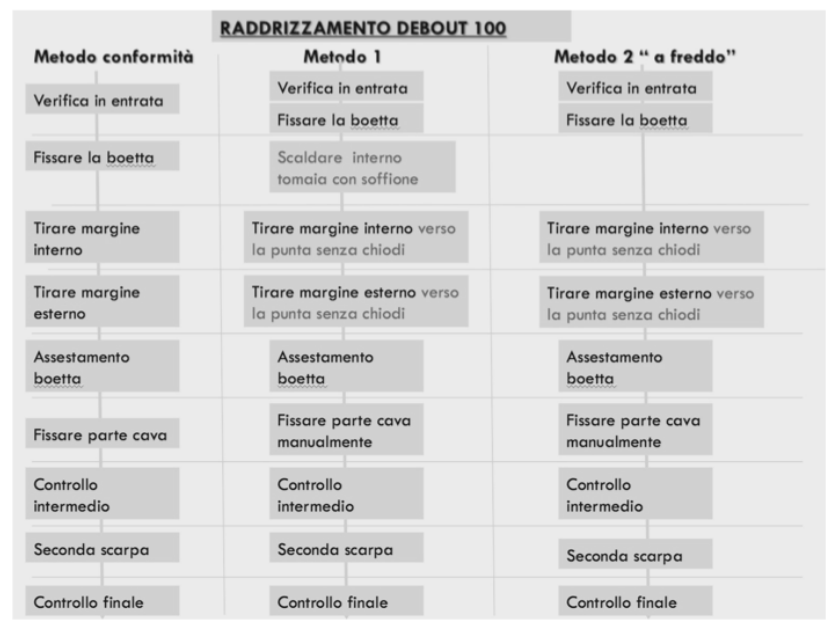

Fig. 8 Different formalised and compared building methods.

There is an obvious temporal displacement of the trainer's action: supporting the discovery of knowledge in action happens at the same time as the action itself, so the focus is on the individual effort to address the problem. Can this be the interpretive key to increasing the action of the trainer? His/her activities for improving professional action, increasing personal and collective consciousness of the interpretation of the work and enabling a collective vision are all supplemented by the establishment of devices designed to enhance an attitude of devolution of the task that is demanding on the operator, who is thus made accountable and valued and is engaged in the development of new knowledge supported by planning and analysis.

This hypothesis is still in the making. Repeated observations of complex situations that jeopardise production quality and quantity will be needed to find out how training in the workplace should assume new approaches, objectives and methodologies that will have a direct impact on the skills of the trainer himself/herself.

\section{Conclusions}

The research intervention undertaken through the vocational education and clinic of activities approach proved effective in companies that wish to remain competitive in a rapidly changing market and which therefore are entering into a process of organisational development. In addition to the results obtained on the intrinsic cognitive potential of the practices and the consequent identification of areas of sustainable enhancement, the ongoing analysis identifies two more changes in the making. The first is a change in the attitude of the subcontracting company with respect to its customer brands. Training gains an important role in raising awareness within the subcontracting company of the intrinsic cognitive potential of the practices and of its usability: when associated with a parallel innovation in the design of the most functional work processes by product families, it enables a review of the company's business approach to its brands, by providing not only an exclusively productive and executive quality service, but by emphasising a consultative role in relation to the feasibility of the product and its viability in a renewed production management process.

The second concerns training action. The experience gained suggests that, in the near future, there will be different trainer functions for

- guiding analysis of the work, understanding the cultural dimension, mostly unconscious and tacit, to lead company stakeholders to explain, reflect on and be aware of their practice. The value of training will be determined by the degree of awareness that it will foster in different subjects on expected and actual practices;

- activating the learning process in the different stages of clarification, validation, joint planning, training and coevaluation, through single, cross-referenced self-encounters to lead the stakeholders to develop a changed culture that operates through the generation of new professional styles and genres;

- accompanying real-time change processes, by supporting the explanation of the inventive processes and by fully enhancing human resources, the real driver of change and source of responses to new situations.

In all cases, it will contribute to the development of a new company-internal collective representation of the value of learning in the workplace as well as of enhancing and utilising the tacit knowledge of the workers, thereby enabling an initial organisational learning process and achieving more effective synergy in the relationship between training and work.

\section{References}

Beguin P., Clot Y. (2004). L’action située dans le développement de l'activité, @ctivités, Vol. 1, n². http://activites.revues.org/1237.

Berthoz A. (2013). La vicariance, Odile Jacob, Paris. 
Cappelletti, L. (2010, Mai). La recherche-intervention: quels usages en contrôle de gestion? Paper presented at Congrès de l'Association francophone de comptabilité (AFC). Retrieved from à http://hal.archivesouvertes.fr/docs/00/48/10/90/PDF/p173.pdf

Carrier, S., \& Fortin, D. (2003). La recherche-intervention pour reconnaître et stimuler une pratique sociale innovante en déficience intellectuelle. Revue francophone de la déficience intellectuelle, 14(2), 175-181

Clot Y. (2008). Travail et pouvoir agir, Paris: PUF.

Clot Y., Faïta D. (2000). Genres et styles en analyse du travail. Concepts et méthodes. Travailler, 4: 7-42

Clot Y., Faïta D., Fernandez G. \& Scheller L. (2000).Entretiens en autoconfrontation croisée: une méthode en clinique de l'activité. Perspectives interdisciplinaires sur le travail et la santé 2-1 Varia

David A. (2000, Mai), La recherche intervention, un cadre général pour les sciences de gestion. IXème Conférence Internationale de Management Stratégique, France, Montpellier.

Dolbec A. \& Prud'Homme L. (2009). Le sens construit autour dela différenciation pédagogique dans le cadre d'une recherche-action-formation. Education et Francophonie, VOLUME XXXIX:2

Leplat, J. (1997). Regards sur l'activité en situation de travail. Paris: PUF.

Magnoler P., Pacquola Mc., Tescaro M. (2014). Knowledge in action for training, Il sapere dell'azione per la formazione. Formazione Lavoro Persona ${ }^{\circ} 12$. Retrieved from http://www.cqiarivista.eu/.

Mérini C. et Ponté P. (Ed) (2008) La recherche-intervention: comme mode d'interrogation des pratiques. In Savoirs. Quel dialogue entre chercheurs et consultants?, 2008/1 (16). L'Harmattan.

Olry, P., \& Parage, P. (Eds). (2008). Analyse du travail et formation. Quelques pratiques en émergence. Éducation Permanente, 174

Olry P. \& Vidal-Gomel C. (2011). Conception de formation professionnelle continue: tensions croisées et apports de l'ergonomie, de la didactique professionnelle et des pratiques d'ingénierie, @ctivités, vol. 8 numéro 2 http://activites.revues.org/2604; DOI: 10.4000/activites.2604

Pacquola Mc., Magnoler P. \& Pacquola B. (2014, octobre). La contribution de la didactique professionnelle à la conception de un dispositif hybride de formation-validation des acquis de l'expérience dans les organisations, Didactique Professionnelle. Paper presented at Troisième Colloque International Conception et formation. France, Caen,

Pacquola Mc., Pacquola B. (2014).Transférer les savoirs d'experience: un chantier italien dans le secteur des chaussures, Travail et apprentissages, 11, Editions Raison et Passions.

Pacquola Mc., Pacquola B. (Eds.) (2014). Le rapport travail et formation dans l'industrie de la chaussure: le cas du Politecnico calzaturiero, Hors-sèrie AFPA"Les synergies travail-formation". Education permanente.

Bru M., Pastré P., Vinatier I. (2007). Les organisateurs de l'activité enseignante, Recherche \& formation, $3,56$.

Pastré P. (2011) La didactique professionnelle. Approche anthropologique du développement chez les adultes, Paris: PUF.

Pastré P., (Ed) (2011). La didactique professionnelle. Un point de vue sur la formation et la professionnalisation. In Competenza e professionalità, Education sciences \& society, Anno 2, n 1 . Armando Editore.

Pastré P., Mayen P., Vergnaud G. (2006). La didactique professionnelle. Revue française de pédagogie, 154, janvierfévrier-mars 2006, 145-198.

Rabardel P. (Ed) (1995). Les hommes et les technologies: une approche cognitive des instruments contemporains, Armand Colin, 1995

Rivoltella P.C. (2014). La previsione. La Scuola Editrice, Brescia.

Samurçay, R., Pastré, P. (1998). L'ergonomie et la didactique. L'émergence d'un nouveau champ de recherche: didactique professionnelle. Paper presented at IIes Journées Recherche et ergonomie: L'ergonomie et les sciences cognitives. L'ergonomie et les sciences de l'homme. Qu'est-ce que la recherche en ergonomie ? France, Université Toulouse-le Mirail.

Samurçay R., Pastré P. (1995). La conceptualisation des situation de travail dans la formation des competences. Le developpement des competences. Education Permanente, 123.

Schwartz Y (Ed) (1997). Reconnaissances du travail: pour une approche ergologique, Paris: PUF.

Simondon G. (Ed) (2012). Du mode d'existence des objets techniques. Aubier.

Tochon F. et Miron J-M. (2004) La recherche-intervention éducative: transition entre famille et CPE. Collection Education-Recherche, 13 Sainte-Foy, Que: Presses de l'Université du Québec.

Vidal-Gomel C., Rogalski J. (2007) La conceptualisation et la place des concepts pragmatiques dans l'activité professionnelle et le développement des compétences @ectivités, 2007, vol. 4 numéro 1. http://activites.revues.org/1401. 